\title{
Prediction Model for Compressive Strength Value of Aluminum Honeycomb Materials Joined with \%1 MWCNT Reinforced Epoxy Adhesive
}

\author{
Harun AKKUS* \\ Technical Sciences Vocational School /Amasya University / Turkey
}

Hayrettin DUZCUKOGLU

Technology Faculty / Mechanical Engineering Department / Selcuk University/ Turkey

\section{Omer Sinan SAHIN}

Engineering Faculty / Mechanical Engineering Department / Selcuk University/ Turkey

\section{Article history}

Received:

30.01.2015

Received in revised form: 11.03.2015

Accepted:

12.03.2015

Key words:

Aluminium honeycomb, \%1 mwcnt, Compressive test, Multiple regression model.
In this study, aluminum(Al.) honeycomb composite structures were produced by joining core of different cell width and cell height to lower-upper layers by $1 \%$ multiwall carbon nanotube reinforced(mwcnt) epoxy adhesive. Compressive strength experiments of $\mathrm{Al}$. honeycomb structures were carried out according to ASTM C365 standards using Instron 8081 model pulling device. Compressive strength values (F) are measured. Compressive experiments were performed three times and mean values were calculated. Experimental results shows that compressive force values decrease when cell height is increased while cell width is constant and values increase when height is decreased. When experimental result is analyzed for the same cell height, it is seen that compressive force values decrease while cell width increases and values increase when cell width decreases. Multiple regression prediction model of strength values of Al. composite structure was created using MINITAB14 programme. Logarithmic regression results of multiple regression prediction models were consistent with the results of the experiment with a coefficient of determination of $97.7 \%$.

\footnotetext{
* Correspondence: harun.akkus@amasya.edu.tr
} 


\section{Introduction}

Composite sandwich structures consist of light core material compressed between two hard surfaces. There are two kinds of core structures: foam and honeycomb. Sandwich composite structures have a wide range of uses with regard to materials they contain and their characteristics. Composite surfaces are usually made of plastic reinforced with dense laminated fibers. In the field of aviation, the first sandwich structure was used during World War II in the wings and body of the first multi-purpose military aircraft Havilland Mosquito. The surfaces of this first structure were made of plywood and the core was made of balsa wood [1]. In course of time, interest on honeycomb structures has increased steadily and they have begun to be used in many areas such as construction, furniture, astronomy, navigation and trains $[2,3]$. In order to learn the mechanical properties of honeycomb structures and lay down stated conditions, which will enable honeycombs to be used, experimental and numerical analysis model studies still continue in light of emerging technologies [4].

The experiments resulted in resistance to impact of honeycomb material, the resistance to compressive, bending resistance, adhesion properties, there are answers to issues such as the response to various conditions [5-8]. The assay was then used to generate results or predictive model is simulated by computer. These results contribute to the honeycomb material to go a step further.

At present, honeycomb structures are widely used owing to their some properties such as high "flexural stiffness/weight" ratio, durability and lightness [9]. In addition, they can be used as energy absorbers in accidents [10]. Honeycomb structures, which are one of the sandwich structures, have a very thin honeycomb core and can be made of aluminum, nomex and cupper [11]. Core structure consists of hexagon, triangle, zigzag and tetragon structures. Core is joined to lower-upper layers by using various adhesives to produce honeycomb structures [12].

Some parameters such as cell density, cell width, cell length, core material and upperlower layers' coverage material and filling of cell spaces with a suitable material substantially affect the mechanical properties of honeycomb structures [13]. Some tests such as compressive, impact, bending and peel are performed to determine the mechanical properties of honeycomb structures $[14,15]$. Experiments showed that applying foam filling between honeycombs and decreasing cell width increase compressive forces, impact forces and bending forces $[16,17]$.

Adhesives used in creating honeycomb structures are important in providing rigidity [18]. Adhesive must be strong enough to maintain force transmission between upperlower layers and core in case of an impact on honeycomb structure. Many alternative adhesives are used to join structures. One of recently used alternative adhesives is nano adhesives [19]. Some particles such as carbon nano tube, added to adhesive, effect the reaction of structures against impacts positively by increasing adherence property [20].

Model for regression analysis contains dependent (stated) and non-dependent (expository) variables [21]. In such a model; change in dependent variable is explained via non-dependent variables [22].

In this study, reactions of aluminum honeycomb structures, which are produced by using $1 \%$ mwent reinforced epoxy adhesives, against compressive were studied. Individual experimentation of each cell height and width is a limitation with regard to cost and time. Multiple regression models were formed to eliminate this limitation, define the relationships between experimental parameters and form

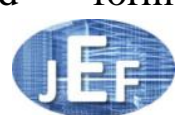


mathematical prediction model.

\section{Materials and Methods}

Core consisted of Al. 3000 series with four different cell width of 6,78-10,39-14,17$17,32 \mathrm{~mm}$ and two different cell height of 10$30 \mathrm{~mm}$; upper-lower layers consisted of $\mathrm{Al}$. 1000 series with $0,5 \mathrm{~mm}$ thickness. The list of experiment is presented in Table 1. In order to produce $1 \%$ mwcnt reinforced epoxy adhesive, mwcnt was dissolved in acetone, mixed for 30 minutes using ultrasonic mixer and put in a cooling bath. Then, it was incubated in $65{ }^{\circ} \mathrm{C}$ vacuuming oven for 24 hours to extract acetone. mwcnt added to epoxy adhesive was $50 \mathrm{~nm}$ in diameter, 10$30 \mu \mathrm{m}$ in length and supplied from Times Nano Company. Before applying adhesive, surface roughness of upper and lower layers was achieved by using P100 sandpaper to enable core to attach more strongly. After this procedure, sanding dust of surfaces was removed using Sika Activator 205 (Sika Cleaner 205). Obtained adhesives were mixed with hardener in a ratio of $2: 1$, applied on the lower layer by using a lectern and core was placed on it. Then adhesive applied upper layer was placed on the core. Formed honeycomb composite structures were incubated under pressure in room temperature for 3 hours for first curing and in 15 bar pressure room temperature for 1 day for the last curing. Samples were pasted to $1 \times 1$ meter Al. layers in size of four cells and cut with a saw to obtain $100 \times 100 \mathrm{~mm}$ size for compressive experiment. Compressive tests were performed using Instron 8081 pulling device according ASTM C365 standards. Produced samples and connection of the samples to test device is shown in Figure 1.

Table 1. Experimental list

\begin{tabular}{|c|c|c|}
\hline Experimental Number & $\mathbf{D}(\mathbf{m m})$ & $\mathbf{h}(\mathbf{m m})$ \\
\hline $\mathbf{1}$ & 6,78 & 10 \\
\hline $\mathbf{2}$ & 6,78 & 30 \\
\hline $\mathbf{3}$ & 10,39 & 10 \\
\hline $\mathbf{4}$ & 10,39 & 30 \\
\hline $\mathbf{5}$ & 14,17 & 10 \\
\hline $\mathbf{6}$ & 14,17 & 30 \\
\hline $\mathbf{7}$ & 17,32 & 10 \\
\hline $\mathbf{8}$ & 17,32 & 30 \\
\hline
\end{tabular}

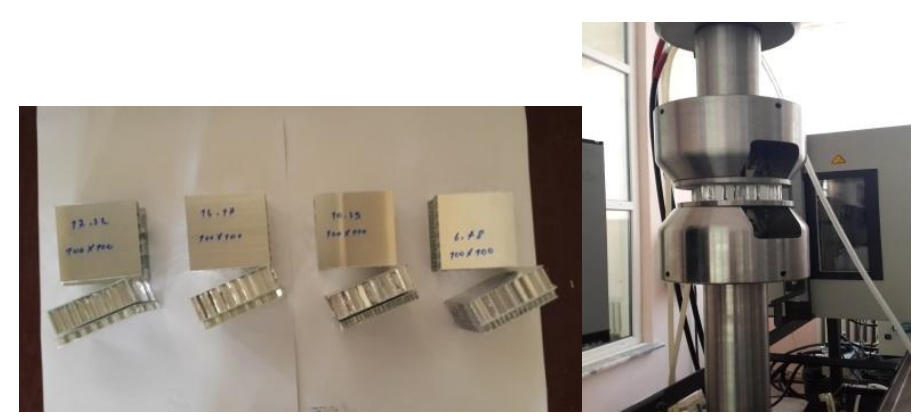

Figure 1. The produced samples and connecting it to samples of the test device

\section{Experimental results}

Force values were measured after compressive experiments. Compressive experiments were performed three times and mean values were calculated. Results are shown in Table 2. 
Table 2. Test results obtained the strength values

\begin{tabular}{|c|c|c|c|}
\hline Experimental Number & $\mathbf{D}(\mathbf{m m})$ & $\mathbf{h}(\mathbf{m m})$ & $\mathbf{F}(\mathbf{k g f})$ \\
\hline $\mathbf{1}$ & 6,78 & 10 & 1949,09 \\
\hline $\mathbf{2}$ & 10,39 & 10 & 1232,71 \\
\hline $\mathbf{3}$ & 14,17 & 10 & 766,33 \\
\hline $\mathbf{4}$ & 17,32 & 10 & 499,21 \\
\hline $\mathbf{5}$ & 6,78 & 30 & 1434,99 \\
\hline $\mathbf{6}$ & 10,39 & 30 & 923,24 \\
\hline $\mathbf{7}$ & 14,17 & 30 & 442,86 \\
\hline $\mathbf{8}$ & 17,32 & 30 & 369,09 \\
\hline
\end{tabular}

Table 2 shows that compressive force values decrease when cell height is increased while cell width is constant and values increase when height is decreased. When Table 2 is analyzed for the same cell height, it is seen cell width increases and values increase when cell width decreases. Figure 2 shows the change in the shape of the sample after experiment, both in the device and separate from the device. that compressive force values decrease while

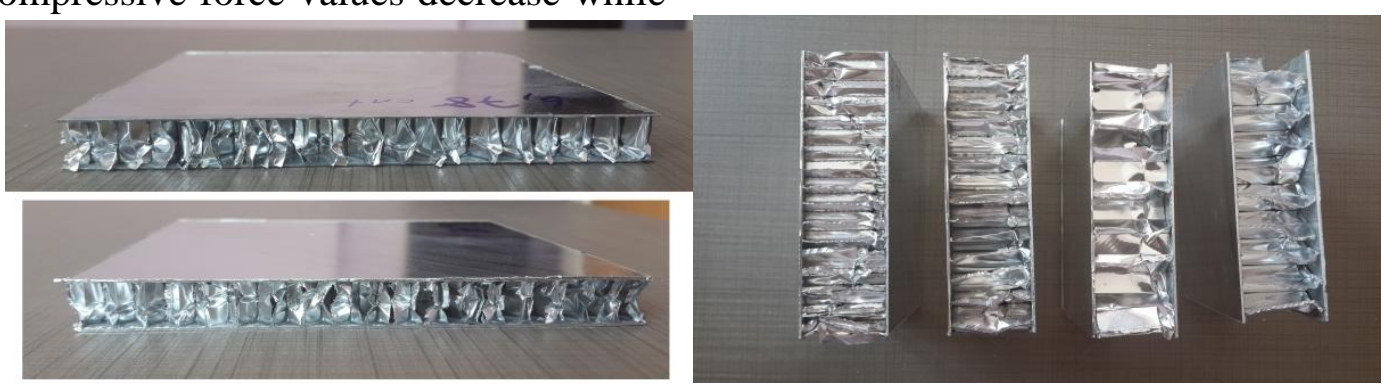

Figure 2. Experimental results the changes occurring in the samples

\section{Regression equations}

Findings achieved by multiple regression equations:

- Coefficient of determination $\left(\mathrm{R}^{2}\right)$ non-dependent variables' declaration ratio for dependent variables is the ratio of the amount of declared to the amount of non-declared in the model. When coefficient of variables in the regression results approaches to 1 , most of the change in dependent variable can be explained by nondependent variable.

- "Coef" expresses the coefficients of the values. Regression coefficient expresses the amount of effect created by one unit change in non-dependent variable on dependent variable,
- "Coef SE" expresses standard error in coefficients,

- Results of "T" test statistics for constant and regression coefficient,

- "P" tests the significance of regression analysis. $\mathrm{P}<0,05$ means that non-dependent variable has effect on dependent value in regression equation,

- "Sum of squares" expresses summation of squares,

- "Mean square" expresses mean of squares

- "df" expresses degree of freedom,

- "Sig." expresses reliability [21].

\subsection{First degree regression equation of $F$}

1st degree regression equation for $\mathrm{F}$ values is 
given in equation (3). 1st degree regression

3. equation coefficients are presented in Table

$\mathrm{F}=2740-121 * \mathrm{D}-16 * \mathrm{~h}$

Table 3. First degree from the regression equation coefficients for $F$

\begin{tabular}{|c|c|c|c|c|}
\hline Predictor & Coef & SE Coef & T & P \\
\hline Constant & 2740,1 & 201,7 & 13,59 & 0,000 \\
\hline D & $-120,73$ & 13,4 & $-9,01$ & 0,000 \\
\hline h & $-15,965$ & 5,309 & $-3,01$ & 0,030 \\
\hline
\end{tabular}

Coefficient of determination in 1st degree effective non-dependent variable affecting $\mathrm{F}$ regression equation for $\mathrm{F}$ is $94.7 \%$. Since it is dependent variable in 1 st degree regression close to 1 , there is a strong relationship equation $(\mathrm{p}<0,5)$. ANOVA table on between variables. $94.7 \%$ of change in MINITAB 14 programme concludes that 1st dependent variable can be explained by non- degree regression equation is confidential. dependent variables. Cell width is the most Table 4 shows ANOVA.

Table 4. First degree from the regression ANOVA results

\begin{tabular}{|l|c|c|c|c|c|}
\hline Source & DF & Sum of squares & Mean square & F & P \\
\hline Regression & 2 & 2032860 & 1016430 & 45,08 & 0,001 \\
\hline Residual Error & 5 & 112733 & 22547 & & \\
\hline Total & 7 & 2145593 & & & \\
\hline
\end{tabular}

4.2. Logarithmic regression equation for $F$

Logarithmic regression equation for $\mathrm{F}$ values

$$
\mathrm{F}=5135-3166 * \log (\mathrm{D})-669 * \log (\mathrm{h})
$$

Table 5. Logarithmic regression equation coefficients for $F$

\begin{tabular}{|l|l|l|l|l|}
\hline Predictor & Coef & SE Coef & T & P \\
\hline Constant & 5134,7 & 303,8 & 16,9 & 0,000 \\
\hline $\log (\mathbf{D})$ & $-3165,5$ & 227,6 & $-13,91$ & 0,000 \\
\hline $\log (\mathbf{h})$ & $-669,2$ & 146,6 & $-4,57$ & 0,006 \\
\hline
\end{tabular}

Coefficient of determination in logarithmic effective non-dependent variable affecting $\mathrm{F}$ regression equation for $\mathrm{F}$ is $97,7 \%$. Since it is close to 1 , there is a strong relationship between variables. $94.7 \%$ of change in dependent variable can be explained by nondependent variables. Cell width is the most dependent variable in logarithmic regression equation $(p<0,5)$. ANOVA table on MINITAB 14 programme concludes that logarithmic regression equation is confidential. Table 6 shows ANOVA.

Table 6. Logarithmic regression ANOVA results

\begin{tabular}{|l|c|c|c|c|c|}
\hline Source & DF & Sum of squares & Mean square & F & P \\
\hline Regression & 2 & 2096675 & 1048337 & 107,15 & 0,000 \\
\hline Residual Error & 5 & 48918 & 9784 & & \\
\hline Total & 7 & 2145593 & & & \\
\hline
\end{tabular}


4

\section{.3. Comparing the results of regression equations for $F$}

Calculations made after mathematical expressions obtained from 1 st degree and logarithmic regression equations for $\mathrm{F}$ are presented in Table 7. Figure 3 shows graph of the results. Analysis of Table 7 and Figure 3 indicates that logarithmic regression equation is closer to results of the experiment.

Table 7. Experimental F, I st degree regression and logarithmic regression results

\begin{tabular}{|c|c|c|c|}
\hline Experimental Number & Experimental F (kgf) & I. degree F (kgf) & LogarithmicF (kgf) \\
\hline $\mathbf{1}$ & 1949,09 & 1759,62 & 1834,33 \\
\hline $\mathbf{2}$ & 1232,71 & 1322,81 & 1247,40 \\
\hline $\mathbf{3}$ & 766,33 & 865,43 & 820,76 \\
\hline $\mathbf{4}$ & 499,21 & 484,28 & 544,76 \\
\hline $\mathbf{5}$ & 1434,99 & 1439,62 & 1515,13 \\
\hline $\mathbf{6}$ & 923,24 & 1002,81 & 928,20 \\
\hline $\mathbf{7}$ & 442,86 & 545,43 & 501,57 \\
\hline $\mathbf{8}$ & 369,09 & 164,28 & 225,56 \\
\hline
\end{tabular}

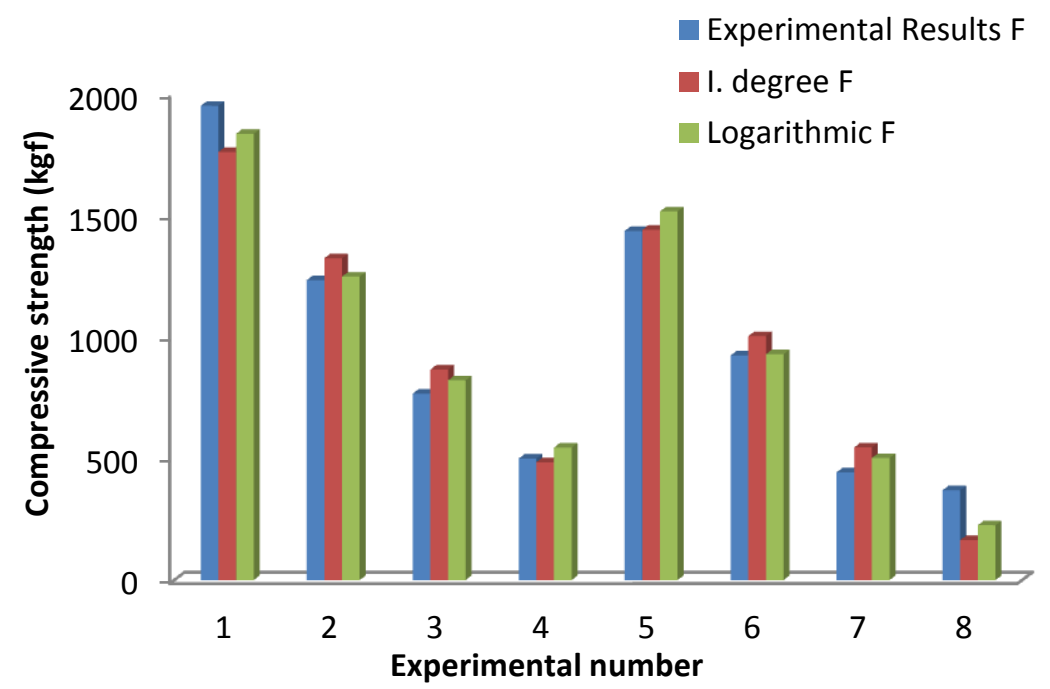

Figure 3. The experimental F, the first degree of regression and logarithmic regression results

\section{Conclusions}

In this study, reactions of hexagon honeycomb composites to compressive were shown using multiple regression models. Results obtained by experiments and multiple regression models are below.

- It was concluded that increasing cell height, while cell width is constant, decreases force values.

- For same cell heights, increase in cell width decreases force values.
- Coefficient of determination in $1 \mathrm{st}$ degree regression equation for $\mathrm{F}$ is $94.7 \%$. Cell width is the most effective non-dependent variable affecting $\mathrm{F}$ dependent variable in $1 \mathrm{st}$ degree equation $(\mathrm{p}<0,5)$.

- Coefficient of determination in logarithmic regression equation for $\mathrm{F}$ is $97.7 \%$. Cell width is the most effective non-dependent variable affecting $\mathrm{F}$ dependent variable in logarithmic regression equation $(\mathrm{p}<0,5)$. 
- When 1st degree and logarithmic regression equations for $F$ are considered, it is seen that logarithmic regression equation results are closer to experimental results with its coefficient of determination of $97,7 \%$.

- It is advised to develop the system by changing honeycomb structure (different cell width, different cell height, different honeycomb material, filled honeycombs, empty layered core, different adhesive) and using different prediction models (artificial neural network, fuzzy logic).

\section{Acknowledgement}

This work was supported by the project number 13201066 Coordinatorship of Selcuk University's Scientific Research Projects.

\section{References}

[1] Aktay L., Johnson A.F., Kroplin B.H. Numerical modelling of honeycomb core crush behavior. Engineering Fracture Mechanics 2008; Vol. 75, pp. 2616-2630.

[2] Rao K.K., Rao J.K., Gupta K.S.A. Heat insulation analysis of an aluminium honeycomb sandwich structure. Journal of Thermal Engineering Yıldız Technical University Press, Istanbul, Turkey 2014; Vol. 1, No. 3, pp. 210-220.

[3] Yin H., Wen G., Hou S., Chen K. Crushing analysis and multiobjective crashworthiness optimization of honeycombs-filled single and bitubular polygonal tubes. Materials and Design 2011; Vol. 32, pp. 44494460.

[4] Wang Z., Tian H., Lu Z., Zhou W. High-speed axial impact of aluminum honeycomb - Experiments and simulations, Composites Part B 2014; 56, pp. 1-8.

[5] Asadi M., Walker B., Shirvani H.,Asadi M. An investigation to compare the application of shell and solid element honeycomb model in ODB. $7^{\text {th }}$ European LS-DYNA Conference, 2009.

[6] CrupiV., Epasto G., Guglielmino E. Comparison of aluminium sandwiches for lightweight ship structures: Honeycomb vs. foam. Marine Structures 2013; Vol. 30, 7496.

[7] Giglio M., Manes A., Gilioli A. Investigations on sandwich core properties through an experimentalnumerical approach. Composites Part B 2012; Vol. 43, 361-374.

[8] Jen Y.M., Chang, L.Y. Effect of thickness of face sheet on the bending fatigue strength of aluminum honeycomb sandwich beams.Engineering Failure Analysis2009; Vol. 16, 1282-1293.

[9] Hong S.T., Pan J., Tyan, T., Prasad P. Dynamic crush behaviors of aluminum honeycomb specimens under compressive dominant inclined loads. International Journal of Plasticity 2008; pp. 89-117.

[10] Zhou Q., Mayer R. Characterization of aluminum honeycomb material failure in large deformation compressive, shear, and tearing. Journal Engineering Materials Technology, 2002.

[11] Roy R., Nguyen K.H., Park Y.B., Kweon J.H., Choi J.H. Testing and modeling of Nomex ${ }^{\mathrm{TM}}$ honeycomb sandwich panels with bolt insert. Composites: Part B 2014; 56, pp. 762-769.

[12] Yahayaa M.A., Ruan D., Lu G., DarguschM.S. Response of aluminium honeycomb sandwich panels subjected to foam projectile impact-an experimental study. International Journal of Impact Engineering 2015; 75, pp. 100-109.

[13] Solmaz M.Y., Kaman M.O., Turan K., Turgut A. Investigation of bending behaviours of honeycomb 
sandwich panels. FrratUniversity Journal of Engineering, 2010; 22, pp. 1-11.

[14] Zhou G., Hill M.D. Impact damage and energy absorbing characteristics and residual in-plane compressive strength of honeycomb sandwich panels. Journal of Sandwich Structures and Materials, 2009; Vol. 11, pp. 329-356.

[15] Nia A.A., Sadeghi M.Z. The effects of foam filling on compressive response of hexagonal cell aluminum honeycombs under axial loadingexperimental study. Materials and Design, 2010; Vol. 31, pp. 12161230.

[16] Zhang X., Cheng G., You Z., Zhang H. Energy absorption of axially compressed thin-walled square tubes with patterns. Thin-Walled Structures, 2007; 45, pp. 737-46

[17] Crupi V., Kara E., Epasto G., Guglielmino E., Aykul H. Prediction model for the impact response of glassfibre reinforced aluminium foam sandwiches. International Journal of Impact Engineering, 2015; 77, pp. 97107.

[18] Yu J.L., Wang X., Wei Z.G., Wang E.H. Deformation and failure mechanism of dynamically loaded sandwich beams with aluminium foam core. International Journal of Impact Engineering, 2003; 28, pp. 331-347.

[19] Kaboorani A., Riedl B. Nanoaluminum oxide as a reinforcing material for thermoplastic adhesives. Journal of Industrial and Engineering Chemistry, 2012; Vol. 18, pp. 10761081.

[20] Akkus H., Ekrem M., Karabulut S.E., Duzcukoglu H., Sahin O.S., Avc1 A. Impact behaviour of mwcnt reinforced epoxy adhesive bonded joints made with aluminium. $15^{\text {th }}$ International Materials Symposium (IMSP), 15-17 October, Denizli, Turkey, 2014; pp. 742-748.

[21] Akkus H. Prediction of surface roughness in turning operations using artificial intelligence and statistical methods. Selcuk University Institute of Science, Konya, 2010.

[22] Mandal N., Doloi B., Mondal B., Das R. Optimization of flank wear using Zirconia Toughened Alumina (ZTA) cutting tool: Taguchi method and Regression analysis. Measurement, 2011; pp. 2149-2155. 